Audiology

Neurotology
Audiol Neurotol 2010;15:323-331

DOI: $\underline{10.1159 / 000289571}$
Received: May 8, 2009

Accepted after revision: November 30, 2009

Published online: March 4, 2010

\title{
Depth of Electrode Insertion and Postoperative Performance in Humans with Cochlear Implants: A Histopathologic Study
}

\author{
Joonhan Lee ${ }^{a, b, e} \quad$ Joseph B. Nadol, Jr. ${ }^{a, b, d} \quad$ Donald K. Eddington ${ }^{a-d}$ \\ ${ }^{a}$ Department of Otology and Laryngology, Harvard Medical School, bepartment of Otolaryngology and \\ 'Cochlear Implant Research Laboratory, Massachusetts Eye and Ear Infirmary, Boston, Mass., and ${ }^{\mathrm{d}}$ Speech and \\ Hearing Bioscience and Technology Program, Division of Health Sciences and Technology, Massachusetts \\ Institute of Technology, Cambridge, Mass., USA; ' Department of Otolaryngology, Head and Neck Surgery, \\ Chosun University, College of Medicine, Gwang Ju, South Korea
}

\section{Key Words}

Cochlear implant $\cdot$ Word recognition $\cdot$ Depth of electrode insertion

\begin{abstract}
The depth of electrode insertion of a multichannel cochlear implant has been suggested as a clinical variable that may correlate with word recognition using the implant. The current study evaluates this relationship using the human temporal bone collection at the Massachusetts Eye and Ear Infirmary. Twenty-seven temporal bones of subjects with cochlear implants were studied. Temporal bones were removed at autopsy, fixed and prepared for histological study by standard techniques. Specimens were then serially sectioned, and reconstructed by two-dimensional methods. Three measures of length were made from each subject's reconstruction: (1) depth of insertion (DI) of the cochlear implant electrode array, from the round window to the array's apical tip; (2) inserted length (IL) from the cochleostomy to the apical tip of the array, and (3) cochlear duct length (CDL) from the round window to the helicotrema. The active electrode length (AEL) was defined as the distance between the most apical and most basal electrodes of the array. Stepwise re-
\end{abstract}

gression was used to identify whether subsets of six metrics associated with insertion depth (DI, DI/AEL, DI/CDL, IL, IL/AEL and IL/CDL), duration of deafness, sound-processing strategy, potential for central impairment and age at implantation accounted for significant across-subject variance in the last recorded NU-6 word score measured during each subject's life. Age at implantation and potential for central impairment account for significant percentages of the across-subject variance in NU-6 word scores for the 27 subjects studied. None of the insertion metrics accounted for significant performance variance, even when the variance associated with the other variables was controlled. These results, together with those of previous studies, are consistent with a relatively weak association between electrode insertion depth and speech reception.

Copyright $\odot 2010$ S. Karger AG, Basel

\section{Introduction}

The depth of insertion (DI) of a multichannel cochlear implant has been suggested as a clinical variable that may be correlated with word recognition. A number of reasons for such an association have been postulated. For

\section{KARGER}

(c) 2010 S. Karger AG, Basel

Fax +41613061234 E-Mail karger@karger.ch www.karger.com www.karger.com/aud
Donald K. Eddington, $\mathrm{PhD}$

Cochlear Implant Research Laboratory, Massachusetts Eye and Ear Infirmary 243 Charles Street

Boston, MA 02114 (USA)

Tel. +1 617573 3766, Fax +1 617573 5502,E-Mail don_eddington@meei.harvard.edu 
instance, the hypothesis that deeper insertion may allow stimulation of spiral ganglion cells serving lower frequencies has motivated a number of studies like that of Geier and Norton [1992] where the effect of varying programmed electrodes on speech perception was evaluated. They reported a decrease of $27 \%$ in Central Institute of the Deaf (CID) sentence score when the five most apical electrodes were eliminated. Tong and Clark [1985] reported that greater depths of insertion led to lower place pitch sensations and more natural speech sounds produced by the implant. Blamey et al. [1992] suggested that deeper insertion of the electrode array may improve the perception of speech because of accessing better preserved apical regions of the cochlea. Friesen et al. [2000] measured speech recognition performance as a function of electrode location and reported that CUNY sentence scores decreased significantly as the electrodes were shifted basally, but other speech measures (12 vowels, 16 consonants, NU-6 words, NU-6 phonemes) did not show a significant change with electrode location. Hochmair et al. [2003] carried out acute speech testing of 10 users of the MED-EL COMBI 40+ implant to evaluate the effect of the insertion depth of the cochlear implant electrode on speech perception and reported that average monosyllabic word test scores when stimulating only the basal region of the cochlea were significantly poorer than the scores for all other conditions (12 channels and two different 8-channel arrangements distributed over the whole length of the cochlea). They concluded that stimulation of the apical region of the cochlea supports a significant degree of speech understanding, and that distributing the contacts over the whole length of the cochlea improves speech perception. In contrast, Gani et al. [2007] found that subjects with the deepest insertions performed better on consonant and vowel identification when the two or three most apical electrodes were deactivated.

Direct tests of the hypothesis that electrode insertion depth influences speech reception are relatively few and do not present a consistent picture. Four types of data have been used to estimate the intracochlear position of implanted electrodes. First, using surgeon's reports of the length of the array inserted into the inner ear, Hartrampf et al. [1995] reported poorer monosyllabic word recognition for short $(\leq 12.75 \mathrm{~mm})$ than deep $(\geq 19.5 \mathrm{~mm})$ insertions. Blamey et al. [1992] did not find a significant association between CID sentence reception and insertion lengths ranging from 10 to $25 \mathrm{~mm}$ in the 64 subjects studied. Hodges et al. [1999] reported that insertion lengths ranging from 17 to $25 \mathrm{~mm}$ did not correlate with NU-6 word recognition.
A second type of data, two-dimensional radiographs of the patient's implanted temporal bone made during life, have been used to estimate (1) the total angle of insertion by visualizing the array's tip position from a modified Stenver's view and (2) the length of array inserted by counting the number of electrode contacts from the round window to the electrode tip and multiplying by the known distance between electrodes. Using this approach, Yukawa et al. [2004] reported that duration of deafness and total angle of insertion together accounted for $37 \%$ of the variance in 48 subjects' consonant-vowel nucleusconsonant (CNC) word score.

A third data type used to estimate array insertion depth is cochlear reconstruction based on high-resolution spiral computed tomography scans. Using this approach, Skinner et al. [2002] demonstrated a significant correlation between NU-6 word scores and insertion depth as a percentage of total cochlear length. Finley et al. [2008] using preoperative and postoperative high-resolution CT images to determine the electrode position in each subject's implanted cochlea, reported that increases in insertion depth (basal electrode angular depth) were significantly related to greater numbers of electrodes being located in scala vestibuli, which significantly correlated with reduced CNC scores.

A fourth class of data used to estimate DI is two-dimensional reconstruction of histopathologically prepared human temporal bones. Using this method, Khan et al. [2005] did not find a significant correlation between the DI of the electrode array and the postoperative NU-6 word score in 15 subjects.

The current study was an effort to reevaluate the association between the histopathologically determined DI with the last documented NU-6 word score measured during life. By combining results from the initial Khan et al. [2005] study with those from more recently donated temporal bones, the subject population is increased from 15 to 27.

\section{Material and Methods}

The temporal bones were fixed in $10 \%$ buffered formalin and decalcified in ethylenediaminetetraacetic acid. Those specimens in which the electrode array was left in situ were postfixed in $2 \%$ osmium tetroxide. All specimens were dehydrated in graded alcohols. The specimens in which the electrode array was left in situ were exchanged with propylene oxide and embedded in Araldite, whereas specimens in which the electrode array had been removed before fixation were embedded in celloidin. The embedded specimens were serially sectioned in the horizontal (axial) plane at an average thickness of $20 \mu \mathrm{m}$. Specimens embedded in 
Araldite with the electrode array left in situ were sectioned by a technique previously described [Nadol et al., 1994]. Every tenth section of the specimen embedded in Araldite was either left unstained or stained in toluidine blue $\mathrm{O}$ before mounting on a glass slide. The serial sections were reconstructed by conventional twodimensional methods [Guild, 1921; Nadol, 1988; Schuknecht, 1993]. The total length of the cochlea and the DI of the electrode as measured from the round window were determined from the two-dimensional reconstruction. The DI of the cochlear implant electrode was evaluated by direct microscopic determination of the most apical section in which the electrode was visible. In specimens in which the electrode had been removed prior to histological preparation, the electrode's track was easily identified by a lumen in the remaining fibrotic and/or boney tissue.

In order to assess whether the depth of electrode insertion or the inserted electrode length are associated with speech-reception performance, two electrode-insertion metrics were measured for each subject's two-dimensional reconstruction: DI as the distance from the round window to the most apical tip of the electrode array and inserted length (IL) as the distance from the cochleostomy to the most apical tip of the array. In addition, two lengths used to normalize the IL and DI measures were also defined: cochlear duct length (CDL) as the distance from the round window to the helicotrema as measured in the two-dimensional reconstructions and the active electrode length (AEL) as the distance between the most apical and basal electrodes of the electrode array (fig. 1). The interelectrode spacing specified by the electrode manufacturer was used to compute the following AELs for the implants included in this study: $15.75 \mathrm{~mm}$ (Nucleus 22 and Nucleus 24M), $11.73 \mathrm{~mm}$ (Nucleus 24R), $20 \mathrm{~mm}$ (Ineraid, Richard Symbion), and $15 \mathrm{~mm}$ (Advanced Bionics, Clarion). Four normalized electrode-insertion metrics were computed: IL/AEL, IL/ CDL, DI/AEL and DI/CDL. In the case of IL/AEL, values $<1 \mathrm{im}-$ ply not all contacts are within the cochlea. Even though the six electrode-insertion metrics are each highly correlated with the other, all are included to facilitate comparison with the results from other studies.

The postimplantation NU-6 word scores listed in table 2 were the last available before death. Only postlingually deafened native English speakers were selected. For some subjects, an NU-6 score was not available but was estimated from other speech-reception test results based on a technique described by Rabinowitz et al. [1992].

Stepwise regression was used to identify combinations of the six electrode-insertion metrics (IL, IL/AEL, IL/CDL, DI, DI/AEL, $\mathrm{DI} / \mathrm{CDL}$ ), duration of deafness, sound-processing strategy, potential for central impairment and age at implantation to build regression models that account for significant amounts of the across-subject variance in the NU-6 word scores.

\section{Results}

\section{Clinical Demographics}

As shown in table 1, the causes of deafness were unknown in 8 cases, meningogenic labyrinthitis in 4 cases, temporal bone fracture in 3 cases, otosclerosis in 3 cases, sudden sensorineural hearing loss in 3 cases, endolym-

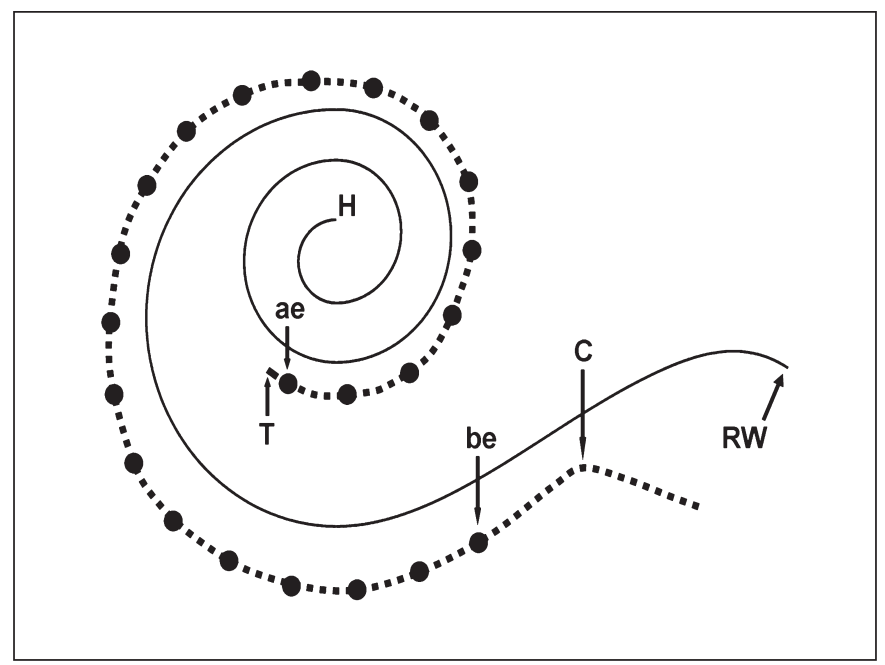

Fig. 1. Specimens and the electrode track were reconstructed by two-dimensional methods. Four measures were calculated: CDL from the round window (RW) to the helicotrema (H); IL from the cochleostomy $(\mathrm{C})$ to the apical tip of the array (T); DI from the round window to the array's apical tip, and AEL from the most apical electrode (ae) to the most basal electrode (be). The solid curved line represents the basilar membrane of the cochlear duct, the dashed line the electrode carrier and filled circles the electrodes.

phatic hydrops in 2 cases, genetically determined hearing loss in 1 case, chronic otitis media in 1 case, mumps and/ or chemotherapy in 1 case, and acoustic schwannoma in 1 case. Bilateral cochlear implants were done in subjects 14 and 17. However, in both, NU-6 word scores were available only for one side. In subject 11, two separate cochleostomies were made during the implantation surgery: a standard Ineraid six-electrode array was inserted through a basal cochleostomy and the Ineraid promontory electrode was placed in the cochlear apex via a separate cochleostomy anterior and inferior to the cochleariform process. However, since stimulation of the promontory electrode was not done clinically, only data for the standard electrode area were used in this study.

Details of implantation and performance are shown in table 2 for each subject: implant type, sound-processing strategy, six electrode-insertion metrics and NU-6 word score. The range and mean for each electrode-insertion metric and the NU-6 score are given at the bottom of table 2. The time from implantation to the day of the last NU-6 test ranged from 3 to 181 months (mean: 57 months).

In the case of subject 2, the data are based on a multichannel cochlear implant placed after explantation of a 
Table 1. Clinical demographics

\begin{tabular}{|c|c|c|c|c|c|c|c|c|c|}
\hline Subject & Etiology & Sex & $\begin{array}{l}\text { Ear } \\
\text { implanted }\end{array}$ & $\begin{array}{l}\text { Age } \\
\text { became } \\
\text { deaf, years }\end{array}$ & $\begin{array}{l}\text { Age } \\
\text { implanted } \\
\text { years }\end{array}$ & $\begin{array}{l}\text { Age at } \\
\text { death } \\
\text { years }\end{array}$ & $\begin{array}{l}\text { Years } \\
\text { deaf }\end{array}$ & $\begin{array}{l}\text { Years } \\
\text { implanted }\end{array}$ & $\begin{array}{l}\text { Months between } \\
\text { implantation and } \\
\text { last NU- } 6 \text { test }\end{array}$ \\
\hline 1 & Unknown & $\mathrm{M}$ & $\mathrm{L}(\mathrm{CL})$ & 47 & 83 & 90 & 36 & 7 & 6 \\
\hline 2 & Temporal bone fracture & $\mathrm{M}$ & $\begin{array}{l}\mathrm{L}(\mathrm{HS}) \rightarrow \\
\mathrm{L}(\mathrm{N} 22)\end{array}$ & 47 & $\begin{array}{l}53(\mathrm{~L}) \\
57(\mathrm{~L})\end{array}$ & 67 & 6 & 14 & 14 \\
\hline 3 & Temporal bone fracture & $\mathrm{M}$ & $\begin{array}{l}\mathrm{R}(\mathrm{I}) \rightarrow \\
\mathrm{R}(\mathrm{I}) \rightarrow \\
\mathrm{R}(\mathrm{N} 22)\end{array}$ & 71 & $\begin{array}{l}71(\mathrm{R}) \\
72(\mathrm{R}) \\
75(\mathrm{R})\end{array}$ & 88 & 0.25 & 17 & 30 \\
\hline 4 & Temporal bone fracture & M & $\mathrm{R}(\mathrm{N} 22)$ & 65 & 65 & 67 & 0.5 & 2 & 25 \\
\hline 5 & Genetics & $\mathrm{M}$ & L (N24) & 49 & 71 & 72 & 22 & 1 & 3 \\
\hline 6 & Mumps, chemotherapy & $\mathrm{F}$ & $\begin{array}{l}\mathrm{R}(\mathrm{N} 22) \rightarrow \\
\mathrm{R}(\mathrm{N} 22)\end{array}$ & 72 & $\begin{array}{l}75(\mathrm{R}) \\
76(\mathrm{R})\end{array}$ & 79 & 3 & 4 & 16 \\
\hline 7 & Meningogenic labyrinthitis & M & $\mathrm{R}(\mathrm{I})$ & 20 & 65 & 72 & 45 & 7 & 66 \\
\hline 8 & Unknown & $\mathrm{F}$ & R (N22) & 71 & 82 & 85 & 11 & 3 & 144 \\
\hline 9 & Sudden SNHL & $\mathrm{F}$ & R (N22) & 47 & 59 & 74 & 12 & 15 & 181 \\
\hline 10 & Otosclerosis & $\mathrm{F}$ & L (N24) & 51 & 65 & 69 & 14 & 4 & 16 \\
\hline 11 & Meningogenic labyrinthitis & $\mathrm{M}$ & $\mathrm{L}(\mathrm{I})$ & 60 & 68 & 71 & 8 & 3 & 25 \\
\hline 12 & Chronic otitis media & $\mathrm{F}$ & $\begin{array}{l}\mathrm{R}(3 \mathrm{M}) \rightarrow \\
\mathrm{R}(\mathrm{N} 22)\end{array}$ & 50 & $\begin{array}{l}65(\mathrm{R}) \\
74(\mathrm{R})\end{array}$ & 80 & 15 & 15 & 60 \\
\hline 13 & Unknown & M & $\mathrm{R}(\mathrm{N} 24)$ & 67 & 82 & 94 & 15 & 12 & 84 \\
\hline 14 & Otosclerosis & $\mathrm{F}$ & $\begin{array}{l}\mathrm{R}(\mathrm{N} 22) \rightarrow \\
\mathrm{L}(\mathrm{N} 24)\end{array}$ & 56 & $\begin{array}{l}56(\mathrm{R}) \\
69(\mathrm{~L})\end{array}$ & 73 & 0.17 & $\begin{array}{c}12(\mathrm{R}) \\
4(\mathrm{~L})\end{array}$ & 7 \\
\hline 15 & Otosclerosis & $\mathrm{M}$ & $\mathrm{L}(\mathrm{I})$ & 65 & 74 & 84 & 9 & 10 & 117 \\
\hline 16 & Sudden SNHL & $\mathrm{F}$ & $\mathrm{R}(\mathrm{I})$ & 38 & 40 & 55 & 2 & 15 & 155 \\
\hline 17 & Meningogenic labyrinthitis & $\mathrm{M}$ & $\begin{array}{l}\mathrm{R}(\mathrm{NS}) \rightarrow \\
\mathrm{L}(\mathrm{N} 22)\end{array}$ & 65 & $\begin{array}{l}68(\mathrm{R}) \\
70(\mathrm{~L})\end{array}$ & 73 & 3 & 5 & 24 \\
\hline 18 & Unknown & $\mathrm{F}$ & L (N22) & child & 54 & 64 & 54 & 10 & 20 \\
\hline 19 & Sudden SNHL & M & $\mathrm{R}(\mathrm{I})$ & 20 & 30 & 47 & 10 & 17 & 144 \\
\hline 20 & Unknown & $\mathrm{F}$ & L (N24) & 84 & 85 & 92 & 1 & 7 & 3 \\
\hline 21 & Ménière’s disease & $\mathrm{M}$ & L (N22) & 61 & 81 & 92 & 20 & 11 & 27 \\
\hline 22 & Schwannoma & $\mathrm{M}$ & $\mathrm{R}(\mathrm{N} 22)$ & 50 & 59 & 70 & 9 & 11 & 26 \\
\hline 23 & Ménière’s disease & $\mathrm{M}$ & R (N24) & 67 & 67 & 70 & 0.17 & 3 & 10 \\
\hline 24 & Meningogenic labyrinthitis & M & $\mathrm{L}(\mathrm{I})$ & 27 & 61 & 77 & 34 & 16 & 147 \\
\hline 25 & Unknown & M & R (N22) & 47 & 77 & 84 & 30 & 7 & 48 \\
\hline 26 & Unknown & $\mathrm{M}$ & $\mathrm{R}(\mathrm{N} 22)$ & 55 & 63 & 75 & 8 & 12 & 125 \\
\hline 27 & Unknown & $\mathrm{M}$ & $\mathrm{L}(\mathrm{CL})$ & 68 & 72 & 78 & 4 & 6 & 28 \\
\hline
\end{tabular}

N22 = Nucleus 22; N24 = Nucleus 24; CL = Clarion; I = Ineraid (Richards Symbion); NS = Nucleus single-channel device; HS = House single-channel device; $3 \mathrm{M}=3 \mathrm{M}$ House single-channel device; $\mathrm{SNHL}=$ sensorineural hearing loss. 
Table 2. Implantation and performance information

\begin{tabular}{|c|c|c|c|c|c|c|c|c|c|c|c|}
\hline Subject & Implant type & Strategy & $\begin{array}{l}\text { Cochleosto- } \\
\text { my, mm }\end{array}$ & $\begin{array}{l}\mathrm{DI} \\
\mathrm{mm}\end{array}$ & $\begin{array}{l}\mathrm{IL} \\
\mathrm{mm}\end{array}$ & $\begin{array}{l}\mathrm{CDL} \\
\mathrm{mm}\end{array}$ & IL/AEL & IL/CDL & DI/AEL & $\mathrm{DI} / \mathrm{CDL}$ & $\begin{array}{l}\text { NU-6 } \\
\%\end{array}$ \\
\hline 1 & Clarion & CIS & 3 & 21.0 & 18.0 & 29.5 & 1.20 & 0.61 & 1.40 & 0.71 & 48 \\
\hline 2 & Nucleus 22 & unknown & 1.5 & 20.2 & 18.7 & 28.5 & 1.19 & 0.66 & 1.28 & 0.71 & $0^{1}$ \\
\hline 3 & Nucleus 22 & SPEAK & 4.5 & 22.5 & 18.0 & 34.3 & 1.14 & 0.52 & 1.43 & 0.66 & 10 \\
\hline 4 & Nucleus 22 & MPEAK & 1.7 & 19.5 & 17.8 & 30.0 & 1.13 & 0.59 & 1.24 & 0.65 & 30 \\
\hline 5 & Nucleus 24R & $\mathrm{ACE}$ & 4.5 & 23.2 & 18.7 & 33.0 & 1.59 & 0.57 & 1.98 & 0.70 & 8 \\
\hline 6 & Nucleus 22 & SPEAK & 4.5 & 21.0 & 16.5 & 31.6 & 1.05 & 0.52 & 1.33 & 0.66 & 16 \\
\hline 7 & Ineraid & CA & 3 & 24.0 & 21.0 & 31.0 & 1.05 & 0.68 & 1.20 & 0.77 & 2 \\
\hline 8 & Nucleus 22 & SPEAK & 4.8 & 20.8 & 16.0 & 33.2 & 1.02 & 0.48 & 1.32 & 0.63 & 34 \\
\hline 9 & Nucleus 22 & SPEAK & 4 & 19.8 & 15.8 & 32.8 & 1.00 & 0.48 & 1.26 & 0.60 & 26 \\
\hline 10 & Nucleus 24M & SPEAK & 5 & 22.0 & 17.0 & 25.5 & 1.08 & 0.67 & 1.40 & 0.86 & 58 \\
\hline 11 & Ineraid & CIS & 4 & 23.0 & 19.0 & 33.9 & 0.95 & 0.56 & 1.15 & 0.68 & 16 \\
\hline 12 & Nucleus 22 & SPEAK & 3.4 & 18.2 & 14.8 & 28.9 & 0.94 & 0.51 & 1.16 & 0.63 & 4 \\
\hline 13 & Nucleus 22 & SPEAK & 4 & 20.0 & 16.0 & 33.4 & 1.02 & 0.48 & 1.27 & 0.60 & 40 \\
\hline 14 & Nucleus $24 \mathrm{M}$ & SPEAK & 4.8 & 18.5 & 13.7 & 26.1 & 0.87 & 0.52 & 1.18 & 0.71 & 24 \\
\hline 15 & Ineraid & CIS & 3.8 & 21.3 & 17.5 & 34.0 & 0.88 & 0.51 & 1.07 & 0.63 & 22 \\
\hline 16 & Ineraid & CIS & 5 & 22.3 & 17.5 & 32.8 & 0.88 & 0.53 & 1.12 & 0.68 & 90 \\
\hline 17 & Nucleus 22 & MPEAK & 5 & 18.0 & 13.0 & 28.1 & 0.83 & 0.46 & 1.14 & 0.64 & 10 \\
\hline 18 & Nucleus 22 & unknown & 3.5 & 16.2 & 12.7 & 28.0 & 0.81 & 0.45 & 1.03 & 0.58 & 56 \\
\hline 19 & Ineraid & CIS & 6.8 & 22.8 & 16.0 & 30.4 & 0.80 & 0.53 & 1.14 & 0.75 & 70 \\
\hline 20 & Nucleus 24M & SPEAK & 3.3 & 16.7 & 13.4 & 30.7 & 0.85 & 0.44 & 1.06 & 0.54 & 6 \\
\hline 21 & Nucleus 22 & SPEAK & 4 & 16.0 & 12.0 & 30.8 & 0.76 & 0.39 & 1.02 & 0.52 & 12 \\
\hline 22 & Nucleus 22 & $\mathrm{~F} 0 / \mathrm{F} 1 / \mathrm{F} 2$ & 3 & 15.0 & 12.0 & 28.4 & 0.76 & 0.42 & 0.95 & 0.53 & 14 \\
\hline 23 & Nucleus 24M & CIS & 3.5 & 15.8 & 12.3 & 30.9 & 0.78 & 0.40 & 1.00 & 0.51 & 58 \\
\hline 24 & Ineraid & CA & 1 & 14.5 & 13.5 & 28.8 & 0.68 & 0.47 & 0.73 & 0.50 & 6 \\
\hline 25 & Nucleus 22 & SPEAK & 3 & 12.0 & 9.0 & 32.6 & 0.57 & 0.28 & 0.76 & 0.37 & 30 \\
\hline 26 & Nucleus 22 & MPEAK & 4 & 11.9 & 7.9 & 35.1 & 0.50 & 0.23 & 0.76 & 0.34 & $18^{1}$ \\
\hline \multirow[t]{4}{*}{27} & Clarion & CIS & 0 & 9.0 & 9.0 & 29.0 & 0.60 & 0.31 & 0.60 & 0.31 & $11^{1}$ \\
\hline & & maximum & 6.8 & 24.0 & 21.0 & 35.1 & 1.20 & 0.68 & 1.47 & 0.86 & 90 \\
\hline & & minimum & 0.0 & 9.0 & 7.9 & 25.5 & 0.50 & 0.23 & 0.60 & 0.31 & 0 \\
\hline & & mean & 3.7 & 18.7 & 15.1 & 30.8 & 0.91 & 0.49 & 1.13 & 0.61 & 26.6 \\
\hline
\end{tabular}

NU-6 = Percentage word score for the last recorded NU-6 word test.

${ }^{1}$ Word score estimated by the method of Rabinowitz et al. [1992].

single-channel device. In subject 27 , because the electrode buckled from the scala vestibuli into the scala tympani in the basal turn, the IL was calculated using the distances between active electrodes.

\section{Sound-Processing Strategy, Duration of Deafness and} Age at Implantation

Given the small number of subjects associated with most of the sound-processing strategies, it is not surprising that a one-way analysis of variance (ANOVA) on the 25 subjects with known sound-processor strategy found the effect of strategy on NU-6 word score not to be significant $[\mathrm{F}(7,17)=1.31, \mathrm{p}=0.30]$. The effect of strategy was also not significant $[\mathrm{F}(1,23)=2.86, \mathrm{p}=0.10]$ when the data were grouped by modern sound-processing strategies (ACE, CIS, SPEAK) and older strategies (CA, F0/F1/F2, MPEAK).

While correlational analysis did not show a significant association between across-subject variance in the duration of deafness and NU-6 scores $\left(\mathrm{r}^{2}<0.001, \mathrm{p}=\right.$ 0.89 ), variance in age at implantation accounted for $24 \%$ of the performance variance $(\mathrm{p}=0.01)$. Figure 2 is a plot of performance as a function of age at implantation and suggests that the significance of the association between these two variables is not very robust and due mainly to the data of the 2 highest performing subjects (subjects 16 and 19). When these 2 subjects are eliminated from the analysis, the association between performance and age at implantation no longer exists $\left(\mathrm{r}^{2}<0.001, \mathrm{p}=\right.$ $0.94)$. 


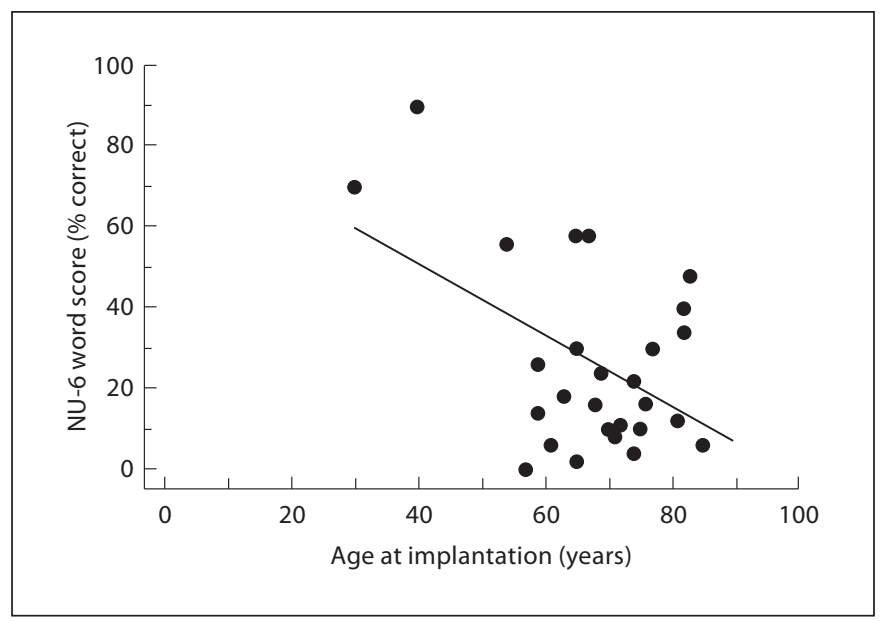

Fig. 2. NU-6 word score plotted as a function of the age at implantation with a linear regression line. While the linear model accounts for $24 \%$ of the performance variance ( $\mathrm{p}=0.01$ ), it can be seen from the plot that the significant correlation is mainly the result of the 2 subjects ( 16 and 19) with age at implantation younger than 50 . When these 2 subjects are removed, the age at implantation no longer accounts for a significant fraction of the acrosssubject performance variance $\left(\mathrm{r}^{2}<0.001, \mathrm{p}=0.94\right)$.

\section{Potential for Central Impairment}

Nine subject histories suggested potential for a central impairment before performance testing that might influence the NU-6 score. Subjects 7, 11, 17 and 24 suffered from meningitis. Subject 2 had a history of grand mal seizure, craniocerebral trauma, reactive depression and a 4-day coma. Subject 8 suffered from Alzheimer's disease, subject 15 from a cerebral vascular accident and subject 20 from dementia. Subject 22 experienced normal-pressure hydrocephalus, ventriculoperitoneal shunt and subarachnoid hemorrhage. Whether or not the subject's history suggested possible central impairment accounted for $20 \%$ of the across-subject performance variance $[\mathrm{F}(1$, $25)=6.27, \mathrm{p}=0.02]$ with the mean word score $(12 \%)$ of the subjects with possible central impairment significantly lower than for the other subjects $[34 \% ; \mathrm{t}(25)=3.18$, $\mathrm{p}=0.004]$.

\section{Electrode-Insertion Metrics}

Correlation analyses were used to determine whether the association between each of the six electrode-insertion metrics (IL, IL/AEL, IL/CDL, DI, DI/AEL and DI/ CDL) and NU-6 word score was strong enough to be significant without controlling for the variance associated with other factors. The Pearson's coefficients of determination $\left(\mathrm{r}^{2}\right)$ and probabilities for the analyses are given in

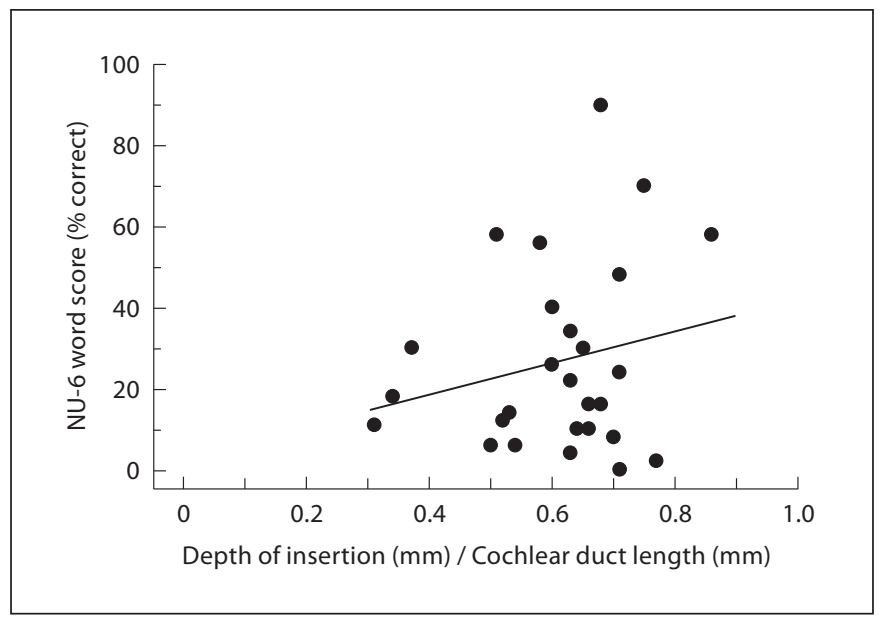

Fig. 3. NU-6 word score plotted as a function of DI normalized by each subject's CDL with a linear regression line. The linear model does not account for a significant fraction of the across-subject performance variance $\left(\mathrm{r}^{2}=0.05, \mathrm{p}=0.27\right)$.

table 3 and show that the very small variance in the NU6 word score accounted for by variance in each of the electrode-insertion metrics was not significant. Figure 3 illustrates the lack of correlation with a plot of the NU-6 score as a function of the DI/CDL metric and the associated regression line.

Stepwise regression was used to identify combinations of the six electrode-insertion metrics (IL, IL/AEL, IL/ $\mathrm{CDL}, \mathrm{DI}, \mathrm{DI} / \mathrm{AEL}, \mathrm{DI} / \mathrm{CDL}$ ) with processing strategy, duration of deafness, duration of strategy use before NU-6 testing, age at implantation or possible central impairment to identify regression models that account for significant amounts of the across-subject variance in the NU-6 word scores. None of the electrode-insertion metrics paired with these variables resulted in combinations in which the effect of the insertion metric was a significant factor in explaining across-subject performance variance. Table 4 illustrates this result by presenting analysis outcomes of six two-parameter models: each of the six insertion metrics paired with possible central impairment. The statistics for the overall model fit show that four of the models account for a significant fraction of performance variance. That this is due to the central-impairment variable with little contribution from the insertion-metric variable is clear when the statistics associated with the effect of the insertion metric (rightmost two columns of table 4) are examined. The insertion-metric effect is not significant for any model. 
Table 3. Pearson's coefficients of determination $\left(\mathrm{r}^{2}\right)$ and probabilities (p) of obtaining a greater correlation by chance $($ d.f. $=26)$ computed between each of the six electrode-insertion metrics and the NU-6 score

\begin{tabular}{lrl}
\hline $\begin{array}{l}\text { Electrode-insertion metric correlated } \\
\text { with NU-6 score }\end{array}$ & \multicolumn{1}{l}{$\mathrm{r}^{2}$} & $\mathrm{p}$ \\
\hline IL & $<0.01$ & 0.82 \\
IL/AEL & 0.01 & 0.70 \\
IL/CDL & $<0.01$ & 0.74 \\
DI & 0.04 & 0.33 \\
DI/AEL & $<0.01$ & 0.89 \\
DI/CDL & 0.05 & 0.27 \\
\hline
\end{tabular}

\section{Discussion}

\section{Electrode Insertion Depth and Performance}

The present analysis of 27 subjects does not reveal any association between electrode-insertion metrics and performance even when the performance variance associated with other variables is controlled. The present results stand in contrast to those of Skinner et al. [2002], the only study reporting a sufficiently strong effect of an electrode-insertion metric (insertion depth normalized by cochlear length) to show a significant correlation $\left(\mathrm{r}^{2}=\right.$ $0.20, p=0.02$ ) with speech reception without controlling for the variance of another predictor variable. Our analysis of the Skinner et al. [2002] data shows that age at implantation was not significantly correlated with performance $\left(r^{2}=0.08, p=0.16\right)$, but when combined with their insertion-depth metric, the percentage of speech-reception variance predicted increases from 20 to $42 \%$ (overall model $\mathrm{p}=0.002$ ) with each effect being highly significant (age at implantation: $\mathrm{p}=0.007$; depth: $\mathrm{p}=0.001$ ).

We are unable to identify a methodological difference between our study and that by Skinner et al. [2002] that might account for the very different results. It is possible that a reduction in variability associated with the subjects of Skinner et al. [2002] - who all used the same implant system (Nucleus 22) and speech-processing strategy (SPEAK) - increased the relative saliency of the insertion-metric's effect. Separate analysis of the 8 subjects from our population with Nucleus 22 implants using the SPEAK strategy and the 11 subjects with straight Nucleus electrodes using the SPEAK strategy did not reveal a significant association of an electrode-insertion metric with NU-6 score.

Skinner et al. [2002] used subject-specific, three-dimensional cochlear reconstructions based on data from
Table 4. Statistics for the multiple regression models computed for the association between the NU-6 word score and the two predictor variables: possible central deficit and the six electrode-insertion metrics

\begin{tabular}{lllllll}
\hline $\begin{array}{l}\text { Electrode-inser- } \\
\text { tion metric }\end{array}$ & \multicolumn{3}{l}{ Overall model fit } & \multicolumn{3}{l}{$\begin{array}{l}\text { Effect of insertion } \\
\text { metric }\end{array}$} \\
\cline { 2 - 4 } \cline { 6 - 7 } & $\mathrm{R}^{2}$ & $\mathrm{~F}(2,24)$ & $\mathrm{p}$ & & $\mathrm{F}(1)$ & $\mathrm{p}$ \\
\hline $\mathrm{IL}$ & 0.22 & 3.39 & $0.05^{*}$ & 0.60 & 0.44 \\
$\mathrm{IL} / \mathrm{AEL}$ & 0.21 & 3.18 & 0.06 & 0.28 & 0.60 \\
$\mathrm{IL} / \mathrm{CDL}$ & 0.22 & 3.47 & $0.05^{*}$ & 0.73 & 0.40 \\
$\mathrm{DI}$ & 0.26 & 4.20 & $0.03^{*}$ & 1.91 & 0.18 \\
DI/AEL & 0.20 & 3.02 & 0.07 & 0.02 & 0.88 \\
DI/CDL & 0.27 & 4.39 & $0.02^{*}$ & 2.21 & 0.15 \\
\hline
\end{tabular}

For the overall model fit: squared multiple correlation coefficients $\left(\mathrm{R}^{2}\right), \mathrm{F}$ ratios $[\mathrm{F}(2,24)]$, and probabilities $(\mathrm{p})$ of obtaining a greater $\mathrm{F}$ value by chance are shown. $\mathrm{F}$ ratios $[\mathrm{F}(1)]$ probabilities (p) associated with the insertion metric. Significance $\left(^{*}\right)$ based on a $\mathrm{p} \leq 0.05$ criterion.

spiral CT scans (100- $\mu \mathrm{m}$ slice intervals) to estimate cochlear canal length and electrode insertion depth. The CT reconstruction methods used to estimate electrodearray length and interelectrode distance have been shown to be in close agreement with measures made using stereo microscopy [e.g., Skinner et al., 1994]. However, the use of radiological data for identification of the cochlear base and the cochleostomy site and the use of Archimedean and equiangular spirals [Ketten et al., 1998] to estimate human cochlear duct length and insertion length have not been tested against direct histological methods. Thus, it is difficult to assess the degree to which the CT methodology might diverge from the histopathological methods used in the present study.

One potential advantage of the radiographic methodology is that measurements are based on premortem data. In the case of histologic preparation of temporal bones removed at autopsy, the specimens are subject to the possibility of some motion or disruption of the in vivo electrode position. We do not think this was an issue in the bones of this study because the electrode track was clearly visible in every bone. Even in bones in which the electrode was removed before processing, the electrode track was easily recognized by a lumen within the electrode's fibrous sheath. A lumen also marked the electrode track in cases where larger masses of soft or boney tissues proliferated around segments of the array. 
Yukawa et al. [2004] combined angular insertion depth with the duration of deafness in their multiple regression analysis of 48 subjects to show a significant effect of insertion depth $(t=2.38, p=0.02)$ and duration of deafness $(t=-4.27, p<0.0001)$. However, our estimate of the correlation between the CNC word-score measures and the measures of angle of insertion from their figure 1 (excluding the same 'outlier' they excluded from their analyses) shows that the effect of insertion depth alone was not strong enough to reach significance $\left(r^{2}=0.06\right.$, $\mathrm{p}=0.17)$ and is similar to our result for insertion depth (table 3; DI: $\mathrm{r}^{2}=0.04, \mathrm{p}=0.33$ ). These results are also similar to those reported by Hodges et al. [1999] for insertions ranging from 17 to $25 \mathrm{~mm}$ in 31 subjects where the correlation with NU-6 word score was not significant $\left(\mathrm{r}^{2}=0.05, \mathrm{p}=0.28\right)$.

A relatively weak electrode-insertion effect is also consistent with studies reporting associations between speech reception and IL or DI that are just sort of significant. The Blamey et al. [1992] study of 64 subjects reported a correlation of $\mathrm{r}^{2}=0.23(\mathrm{p}=0.08)$. The data reported by Finley et al. [2008, fig. 1,4] allowed us to estimate individual $\mathrm{CNC}$ word scores and angular DI measures for the 14 subjects studied. Our estimate of the correlation between word score and DI was also just short of significant $\left(\mathrm{r}^{2}=\right.$ $0.26, \mathrm{p}=0.06$ ).

Taken as a whole, the current study's results and those of previous studies are consistent with a relatively weak association between electrode insertion depth and speech reception that is sometimes revealed when the performance variance associated with other factors (e.g., age at implantation) is controlled, but rarely of sufficient strength to be documented with bivariate analysis.

\section{Impact of Short Insertions on Performance}

The results of Hartrampf et al. [1995] suggest the possibility that the association between performance and insertion length may be stronger when the subject population is limited to implantees with relatively shallow and relatively deep insertion depths. Hartrampf et al. [1995] compared Freiburger monosyllabic word scores between a group of 7 subjects with electrode IL $\leq 12.75 \mathrm{~mm}$ (range: $3.75-12.75 \mathrm{~mm}$ ) and a group of 7 matched (by duration of deafness and age at onset of deafness) subjects with IL $\geq 23.25 \mathrm{~mm}$. They reported a lower mean score for the short IL group (24\%) than for the deeper insertion group (37.8\%). While we could not select matched groups, we did group our subjects into IL quartiles to test whether the mean NU-6 score of the first-quartile group (7.9 $\mathrm{mm} \leq \mathrm{IL}<12.7 \mathrm{~mm}$ ) was lower than any of the other quartile groups. The first-quartile group's mean NU-6 score $(21 \%)$ was not significantly different from the mean scores of the second $(21 \%, t=0.02, p=0.98)$ or fourthquartile groups $(16 \%, t=-0.45, p=0.66)$, but did differ significantly from the third-quartile group $(47 \%, t=2.33$, $\mathrm{p}=0.03$ ) with $16.0 \mathrm{~mm} \leq \mathrm{IL}<17.8 \mathrm{~mm}$. Because similar quartile group analyses for the other electrode-insertion metrics used in this study (DI, DI/AEL, DI/CDL, IL/AEL and IL/CDL) did not show significant differences between the mean NU-6 scores of the first and third quartiles, we suspect that the significant difference found between mean NU-6 score for the first- and third-quartile IL groups reflects a characteristic of the specific population rather than a general characteristic associated with electrode IL or depth.

\section{Other Factors}

In the analyses of our subjects, only age at implantation $(24 \%, \mathrm{p}=0.01)$ and possible central impairment $(20 \%, p=0.02)$ explained a significant percentage of across-subject performance variance. Our analysis of the Finley et al. [2008] results also show a significant association between age at implantation and performance $\left(r^{2}=0.43, p=0.01\right)$, but the Skinner et al. [2002] results do not $\left(\mathrm{r}^{2}=0.08, \mathrm{p}=0.16\right)$.

The duration of deafness has been identified by others as a factor explaining significant across-subject performance variance [e.g. Blamey et al., 1996]. No such association was found in the subjects of the present study $\left(r^{2}<0.001, p=0.89\right)$ or in our analysis of the results of Skinner et al. [2002] $\left(r^{2}=0.07, p=0.17\right)$ or in the reported results (no statistics given) of Finley et al. [2008].

\section{Conclusions}

A significant percentage of across-subject performance variance was explained by age at implantation $(24 \%, \mathrm{p}=0.01)$ and possible central impairment $(20 \%$, $\mathrm{p}=0.02)$ in the 27 subjects of this study. But a significant fraction of the performance variance could not be accounted for by any of the six electrode-insertion metrics (IL, IL/AEL, IL/CDL, DI, DI/AEL, DI/CDL) measured in the subjects' temporal bones, even when the variance associated with other variables like age at implantation, potential central deficit, duration of deafness, processing strategy and duration of strategy use were controlled. These results, together with those of previous studies, are consistent with a relatively weak association between electrode insertion depth and speech reception. For the 
relatively small populations studied to date, this weak association is only sometimes revealed when the performance variance associated with other factors is controlled and is rarely of sufficient strength to be documented with bivariate analysis.

\section{Acknowledgment}

This work was supported by funding from the NIH (NIDCD) grant R01DC000152 Electron Microscopy of the Human Inner Ear.

\section{References}

Blamey P, Arndt P, Bergeron F, Bredberg G, Brimacombe J, Facer G, Larky J, Lindstrom B, Nedzelski J, Peterson A, Shipp D, Staller S, Whitford L: Factors affecting auditory performance of postlinguistically deaf adults using cochlear implants. Audiol Neurootol 1996;1:293-306.

Blamey PJ, Pyman BC, Gordon M, Clark GM, Brown AM, Dowell RC, Hollow RD: Factors predicting postoperative sentence scores in postlinguistically deaf adult cochlear implant patients. Ann Otol Rhinol Laryngol 1992;101:342-348.

- Finley CC, Holden TA, Holden LK, Whiting BR Chole RA, Neely GJ, Hullar TE, Skinner MW: Role of electrode placement as a contributor to variability in cochlear implant outcomes. Otol Neurotol 2008;29:920-928.

-Friesen LM, Shannon RV, Slattery WH: Effects of electrode location on speech recognition with the Nucleus-22 cochlear implant. J Am Acad Audiol 2000;11:418-428.

-Gani M, Valentini G, Sigrist A, Kós MI, Boëx C: Implications of deep electrode insertion on cochlear implant fitting. J Assoc Res Otolaryngol 2007;8:69-83.

Geier LL, Norton SJ: The effects of limiting the number of Nucleus 22 cochlear implant electrodes programmed on speech perception. Ear Hear 1992;13:340-348.
Guild SR: A graphic reconstruction method for the study of the organ of Corti. Anat Rec 1921;22:141-157.

Hartrampf R, Dahm MC, Battmer RD, Gnadeberg D, Strauss-Schier A, Rost U, Lenarz T: Insertion depth of the nucleus electrode array and relative performance. Ann Otol Rhinol Laryngol 1995;166(suppl):277-280.

Hochmair I, Arnold W, Nopp P, Jolly C, Muller J, Roland P: Deep electrode insertion in cochlear implants: apical morphology, electrodes and speech perception results. Acta Otolaryngol 2003;123:612-617.

Hodges AV, Villasuso E, Balkany T, Bird PA, Butts S, Lee D, Gomez O: Hearing results with deep insertion of cochlear implant electrodes. Am J Otol 1999;20:53-55.

Ketten DR, Skinner MW, Wang GE, Vannier MW, Gates GA, Neely JG: In vivo measures of cochlear length and insertion depth of Nucleus cochlear implant electrode arrays. Ann Otol Rhinol Laryngol 1998; 175 (suppl):1-16.

Khan AM, Handzel O, Burgess BJ, Damian D, Eddington DK, Nadol JB Jr: Is word recognition correlated with the number of surviving spiral ganglion cells and electrode insertion depth in human subjects with cochlear implants? Laryngoscope 2005;115:672-677.

Nadol JB Jr: Quantification of human spiral ganglion cells by serial section reconstruction and segmental density estimates. Am J Otolaryngol 1988;9:47-51.
Nadol JB Jr, Ketten DR, Burgess BJ: Otopathology in a case of multichannel cochlear implantation. Laryngoscope 1994;104:299303.

Rabinowitz WM, Eddington DK, Delhorne LA, Cuneo PA: Relations among different measures of speech reception in subjects using a cochlear implant. J Acoust Soc Am 1992;92: 1869-1881.

Schuknecht HF: Pathology of the Ear, ed 2. Philadelphia, Lea \& Febiger, 1993.

Skinner MW, Ketten DR, Holden LK, Harding GW, Smith PG, Gates GA, Neely JG, Kletzker GR, Brunsden B, Blocker B: CT-derived estimation of cochlear morphology and electrode array position in relation to word recognition in Nucleus-22 recipients. J Assoc Res Otolaryngol 2002;3:332-350.

Skinner MW, Ketten DR, Vannier MW, Gates GA, Yoffie RL, Kalender WA: Determination of the position of Nucleus cochlear implant electrodes in the inner ear. Am J Otol 1994;15:644-651.

-Tong YC, Clark GM: Absolute identification of electric pulse rates and electrode positions by cochlear implant patients. J Acoust Soc Am 1985;77:1881-1888.

Yukawa K, Cohen L, Blamey P, Pyman B, Tungvachirakul V, O’Leary S: Effects of insertion depth of cochlear implant electrode upon speech perception. Audiol Neurootol 2004;9: $163-172$. 